\title{
Importance of Positive Lifestyle in Achieving Righteous Way of Living
}

\author{
Sahil Sharma \\ Physical Education Teacher Department of Youth Services and Sports, Govt. of Jammu and Kashmir, Jammu and Kashmir, India \\ Email address: \\ krishmasuri1119@gmail.com \\ To cite this article: \\ Sahil Sharma. Importance of Positive Lifestyle in Achieving Righteous Way of Living. International Journal of Science and Qualitative \\ Analysis. Vol. 6, No. 1, 2020, pp. 13-15. doi: 10.11648/j.ijsqa.20200601.13
}

Received: February 26, 2020; Accepted: March 23, 2020; Published: May 28, 2020

\begin{abstract}
In this paper we will focus on the importance of positive lifestyle and what are the components that are required to have a positive lifestyle. Positive lifestyle is a combination of positive attitude, positive action, positive vibes and positive environment. It is said that who are rich can have positive lifestyle but it is not really true. Various factors such as age, education, occupation, and family income influence the positive lifestyle as well as life satisfaction. Positive lifestyle would offer important direction for the growth of life satisfaction. This is what we have discussed in this paper. Every individual regardless of its financial conditions can have a positive lifestyle. Living a positive lifestyle and having a positive attitude requires a combination of healthy eating by knowledge of nutrition and appropriate amount of physical activities [11]. In this paper, we have discussed the knowledge of nutrition by balanced diet and the important of physical activities in leading a positive lifestyle. We have also discussed how the positive lifestyle helps in achieving the success. Success is an important part of life and it is impossible to get it without a positive lifestyle, positive vibes and positive environment. Positive lifestyle is a new outlook to see the world and to see your own self.
\end{abstract}

Keywords: Lifestyle, Positivity, Success, Vibes, Stress, Physical Fitness, Well Being Etc

\section{Introduction}

Successful is not merely a word, it is a desire of every human being present in this world but still everyone does not have it. Now the question arises.

"Why it is so?"

"Why everyone does not get it even after working so hard?"

The answer lies in the lifestyle of the successful peoples. If one tries to look closer into the life of successful peoples, they will clearly see one thing common among all and that is a positive lifestyle [6]. A positive lifestyle comes from positive attitude. Positive lifestyle is precious for all of us for leading a healthy and successful life. The terminology like positive thinking, positive attitude and optimism are used interchangeable quite often to describe successful peoples [7] Positive lifestyle is useful for achieving success. Positive lifestyle brings a drastic change in the life of an individual. It gives the individual what they desire. It helps in fulfilling all the wishes an individual dream off.

\section{Aim of the Study}

The aim of the study is to know:

i. What is positive lifestyle?

ii. What are its components?

iii. What is its importance?

iv.How positive lifestyle helps in achieving the success?

\section{Meaning of Positive Lifestyle}

In dictionary lifestyle means a manner of living that reflects the person's value and attitude. Positive lifestyle is a manner of living with a positive spirit and encouragement. Positive lifestyle means positive attitude, positive thoughts, positive vibes and positive actions. A positive lifestyle means a positive outlook for every problem that means when you encounter with a problem you try to solve them instead of worrying about the problem.[5] It will help you to improve yourself throughout the life because every problem brings a new lesson to teach. We learn from our failures and move 
ahead to achieve the success.

Positive lifestyle can be adopted at any age, at any circumstances whether financial conditions are favorable or not. [2] You need not be worry about it. It is just an outlook to see the world. You have to change your outlook. You have to accept everything as it is. You have to cease the habit of being judgmental and criticize others for their negative points You try to find out all the positive points among them. You will notice that there are more positive points in an individual as compare to their negative points.

Financial wellbeing is not a point due to which we will have a positive lifestyle. Without being financially sound, we can have a positive lifestyle. What we need is to change some habits and be positive in every circumstance [9]. We know it is extremely difficult to be positive in every situation but we can try to be.

\section{Components of Positive Lifestyle}

For having a positive lifestyle following components are to be considered:

\subsection{Positive Attitude}

Positive attitude is a very essential component and is a key to positive life. A positive attitude is seeing the glass half full. It means to keep a set of thoughts, ideas and values that tend to look for the good, to overcome problems, to find the opportunities in every situation, to look on the bright side of life, to face any kind of situations etc [2]. People with a positive outlook on life can accomplish just about anything. They don't let doom and groomers take their dreams away.

\subsection{Balanced Diet}

Balanced diet is similar to healthy diet which includes fresh fruits and vegetables, whole grain food, dry fruits, fat free and low fat dairy products [1]. This diet is necessary to maintain sufficient amount of vitamins, minerals and nutrients that are needed to have a healthy body. By having a balanced diet, our body will be free from diseases and it is a step towards positive lifestyle. It is said that a sound mind lives in a sound body; it means if we are physically healthy then only we are mentally healthy and both are essential for positive lifestyle.

\subsection{Exercise and Participation in Sports and Games}

It is another vital component of a positive lifestyle. Regular exercise is needed to maintain the fitness of the body, release tension, increases the focusing capability of an individual. Participating in games and sports helps in reducing the body weight, enhance strength and flexibility of body [1]. It increases the team spirit among players and made them learn how to live in harmony and co-operation with one-another. All these aspects are necessary to lead a positive lifestyle.

\subsection{Personal Hygiene}

It is one of the essential components to live life positively. Personal hygiene is the cleanliness and proper care of eyes, throat, ear, nose, tongue, teeth, nails etc [1]. By personal hygiene, we will be far from diseases and live a healthy and positive life. To live a positive life, personal hygiene plays an important role. It helps to enhance the personality of an individual which create a positive vibes in them.

\subsection{Release Stress}

Stress is the root cause of every problem. Around $70 \%$ of physical and mental problems are due to stress. Stress leads to increase in body weight, heart diseases, mental problems like anxiety, depression, panic attacks etc [1]. Some peoples are more likely to smoke, drink, overeat, argue with others, makes use of drugs in their stress period. So release of stress is essential to live a positive and healthy life. The stress can be released through meditation, participation in co-curricular activities or by counseling etc.

\subsection{Proper Sleep}

Proper sleep is necessary for every individual. Sleep duration depends upon the age of an individual. For children 10-11 hours sleep is mandatory, for teen the duration of sleep should be 8-9 hours, for adults whose age lies between 20-45 years need 7-8 sleep makes a man lazy throughout the day and is one of the important reason for strokes, heart diseases etc. Sleeping more than the time duration is also harmful for the individual.

\subsection{Social Interaction}

It is another significant component of positive lifestyle. Man is a social animal and to maintain social links with his fellows and neighbors is very necessary. To live a positive lifestyle social relations are very important. A person can share his failures with his close relatives and feel relaxed and can be motivated by them. He can also share his victories with his close relatives and have a positive vibes around him.

\section{Importance of Positive Lifestyle}

Positive lifestyle is the precious source of reducing number of problems and their impact in the life of an individual. It is most valuable source to cope up with life stress and for improving the quality of life. But in this fast moving world, we are left with very little time for ourselves [2]. We are bonded with family, friends and work, we care too little time for ourselves. Positive lifestyle helps us to care for ourselves and live life happily.

A healthy or positive lifestyle is very important for all of us in following ways:

1. Increase the life span: It helps to increase the lifespan of an individual. It enhances the immunity of an individual and reduces the risk of various physical and mental problems. It delays the deterioration of health. It slows 
down the rate of aging process.

2. Reduce the mental problems: It helps in reducing the various mental problems. Mental problems such as depression, anxiety and panic attacks are common among the youth. They try to commit suicides due to these mental issues. They see negative things around them. Their mind fails to see and interpret the positivity around them. Positive lifestyle reduces all these risks and individual can feel the positive vibes around them.

3. Increase the body fitness: It helps to increase the body fitness as it includes exercises, participation in games and sports, physical activities etc. All these aspects are necessary to live a positive life and increase the physical fitness of an individual.

4. Increase the self-confidence: In today's world, lack of self confidence is a major issue. It can be cured through a positive lifestyle. It enhances the self esteem of an individual and it makes the individual confident and motivates them to do their best in every aspect of life.

5. Helps in coping with stress: It helps in coping with the stress. Stress is the root of all physical and mental problems. Due to stress, problems like cardiovascular, mental health occur in an individual. With the help of positive life stress can be release through the body and positive attitude is developed in a human being.

6. Increase the energy level: An individual who lives a positive lifestyle feel more energetic. He or she works all day and is more productive in day to day living. Positive attitude makes an individual more creative, makes his or her brain becomes more focused and makes an individual physically more active. Without positive lifestyle an individual is lethargic all day and cannot complete his or her work on him.

7. Helps in reducing depression: Healthy lifestyle helps in achieving a healthy body and healthy body elevates hormone level in the body that regulators the mood of an individual. If an individual is happy and his or her mood is good; he or she can achieve anything in this world. An individual should be mentally strong to survive in this world and healthy lifestyle helps in being mentally strong.

8. Helps in Preventing Cardiovascular Diseases: A healthy lifestyle helps to prevent and cure the cardiovascular diseases. It helps in removing the extra body fat and strengthens the heart, resulting in more oxygen supply to the body. The proper flow of blood throughout the body helps in prevention of various diseases which further results in better quality of life.

\section{Conclusion}

As the conclusion part I can say that there is a big need of positive lifestyle in the life of an individual. If there is a positive attitude among the individuals they will be more creative, energetic and productive. Positive lifestyle is the believing in yourself, focusing on success, learning from failures and surrounding yourself with positive vibes and encouragements [10]. Positive lifestyle gives you everything what you desire about: success, peace of mind, healthy body, more friends etc. positive lifestyle is a new outlook to see the world and to see your own self. You see only the positive things around yourself.

\section{References}

[1] Health and physical education. By: Dr. V. K. Sharma.

[2] A study of understanding the need for positive attitude at workplace. By Gangwar Neha.

[3] Summary of the new world of work research reports 2007. By: Rotterdam school of management, Erasmus university.

[4] Hurlock, B. Elizabeth. 2006. Personality Development. New Delhi. Tata McGraw-Hill Publishing company limited.

[5] Key to a positive attitude. By: Nancy Friedman. www.telephonedoctor.com.

[6] www.mayoclinic.org./healthy_lifestyle/mens-health/indepth/mens-health/art-20047764.

[7] Fredrickson, B. L. (2001). The role of positive emotions in positive psychology. The broaden - and - build theory of positive emotions. American psychologist. Vol. 56, Pp 218226.

[8] Hunter, j. p, \& csikszentmihalyi, M. (2003). The positive psychology of interested Adolescents. Journal of youth and adolescence. Vol. 32, Iss. 1, Pp 27-35.

[9] Luthans, F. (2002). The need for and Meaning of positive organizational Behavior. Journal of organizational Behavior. Vol. 23, Iss. 6, p 695.

[10] Peale, N. V. (1952). The power of positive thinking. Fireside: New York.

[11] Introduction living a healthy lifestyle, SD department of education, https://doe.sd.gov.

[12] Lykken D, Tellegen A. Happiness is a stochastic phenomenon. Psychol sci 1997; 7: 186-9.

[13] A positive attitude is the key to success, DAV Magazine, Date: January 1, 2008, Author: Edwards, Charles w., jr.

[14] The power of positive thinking in business, By: scott W. ventrella, www.bottomlinesecrets.com.

[15] World Health Organization. Charter. Geneva, Switzerland; 1948. 